\title{
Adoption of Business Intelligence to Support Cost Accounting Based Financial Systems - Case Study of XYZ Company
}

https://doi.org/10.1515/eng-2021-0002

Received May 16, 2020; accepted Sep 07, 2020

Abstract: XYZ is a company engaged in the port sector. To support the company's business processes, XYZ uses two applications to carry out operational activities, namely the CARTOS application to manage invoices and the Finance application to record company costs and revenues. To produce a cost accounting report, XYZ is still processing and visualizing it manually with data sources from the two applications mentioned earlier. This resulted in quite a long time processing data into information. So that reporting to management cannot be done in real time. Therefore XYZ needs a system that can help management to analyze and manage data into information in real time. The Business Intelligence (BI) method is one of the solutions for company needs, especially in analyzing and providing access to data to help make better decisions.

This study discusses the design and implementation of business intelligence solutions ranging from architecture, data warehouse, ETL processes and visualization in the form of a dashboard in accordance with the needs of XYZ. The method used in developing business intelligence dashboards refers to the executive information system life cycle method which consists of justification, planning, business analysis, design, construction, and dissemination. The results of this research are dashboard visualization using the Power BI tool that displays information and knowledge needed in the monitoring process and becomes material to produce management decisions related to cost accounting reports.

Keywords: Business Intelligence, Cost Accounting, Dashboard, Executive Information System

\footnotetext{
${ }^{\star}$ Corresponding Author: Ford Lumban Gaol: Doctor of Computer Science Program, BINUS Graduate Program, Bina Nusantara University, Jakarta 11480, Indonesia; Email: fgaol@binus.edu Lufty Abdillah: Master of Management Information System, Binus Graduate Program, Bina Nusantara University, Jakarta 11480, Indonesia; Email: abdillahlufty@gmail.com
}

\section{Introduction}

Business Intelligence (BI) is defined as a technique, technology, system, methodology or application for analyzing critical data of a company that is used to provide accurate and useful information for decision makers within a specified time limit to support decision making [1]. BI can be used to support a large number of business decisions ranging from operations to strategic. Operating decisions include determining the cost of production of a service or product. Strategic decisions include priorities, goals and direction at a broader level. In all cases, BI is more effective when using data from internal company business sources such as operating and financial data (internal data).

Research in the field of BI has been widely carried out by researchers including research on the application of Business Intelligence in the health industry by Foshay in 2014. In his research, Foshay made the Canadian Health Authority a case study to find out the needs of health organizations in the early stages of BI implementation, and created a framework for defining any information needs to support the implementation of business intelligence in the health sector [2]. Hertley in 2011 conducts research into the application of business intelligence to public sector organizations in South Africa [3]. Ali in 2013 researched business intelligence solutions in the health sector by transforming the OLTP (Online Transactional Processing) system into OLAP (Online Analytical Processing). In his implementation Ali used the BI development life cycle methodology, which consisted of data warehouse design, ETL design, Analysis Service design, report design and Data Mining component design [4]. Vajirakachorn in his research conducted the application of business intelligence to the tourism industry, by taking a case study at a local food festival in Thailand. In his research, Vajirakachorn used the $\mathrm{BI}$ framework to combine database ar-

Tokuro Matsuo: Advanced Institute of Industrial Technology; Email: matsuo@aiit.ac.jp 
chitecture, business analysis, business performance management and data visualization to assist analysts in gaining knowledge from festival visitor data [6]. Marcello Mariani in 2018 conduct research into identify critical business problems and links the domains of business intelligence and big data to tourism and hospitality management and development [7]. In his research, Marcello examine the extent to which Business Intelligence and Big Data feature within academic research in hospitality and tourism published until 2016, by identifying research gaps and future developments and designing an agenda for future research. Pall Rikhardsson in 2018 conduct research into business intelligence \& analytics in management accounting research [8]. In his research, Pall Rikhardsson reviews the literature, points to several research gaps and proposes a framework for studying the relationship between BI\&A and management accounting.

The position of this research among previous studies, can be seen from the aspect of the industry that is used as a case study. This Business Intelligence adoption research takes a case study on the port industry in Indonesia. As the object of research is $\mathrm{XYZ}$ company in Jakarta. $\mathrm{XYZ}$ is a company engaged in the port industry. $\mathrm{XYZ}$ is engaged in the business of loading and unloading terminal services and container buildup. As a container loading and unloading service company, XYZ's vision is to become a worldclass container terminal company, which translates into the company's mission to grow and develop with emphasis on customer satisfaction and supported by reliable resources. To realize this goal, XYZ requires a system that can produce financial accounting based on cost accounting that is able to present accurate and detailed data. Cost accounting reports can be used by managers as a basis for determining the cost of production, controlling costs and assisting in making business decisions.

The main problem faced by the port industry companies in Indonesia, especially XYZ, among others, is XYZ requires cost accounting reports to assist in planning and controlling costs, determining the cost of production and making management decisions. Based on the results of interviews with the management of XYZ, there are several issues related to the process, including:

1) Data obtained from the supporting application output mentioned earlier is still in the form of raw data and takes 2 weeks to process data into information because it is done manually.

2) Data that can be stored and processed in Microsoft Excel is limited so that the process of monitoring and viewing historical data is still not optimal.
3) The process of reporting cost accounting reports to management cannot be done in real time.

The information system will be built using Business Intelligence (BI) technology. The methodology used in this study uses the business intelligence roadmap approach based on Moss and Atre research in 2003 [9].

\section{Materials and Methods}

\subsection{Business Intelligence}

Business Intelligence is a way to collect, store, organize, reshape, summarize data and provide information, both in the form of company internal business activity data, as well as company external business activity data including business activities of competitors that are easily accessed and analyzed for various management activities [10].

Business Intelligence is a series of applications and technologies for collecting, storing, analyzing, and presenting data access to assist company officials in decision making [11].

In addition, according to $\mathrm{Dj}$ Powers, said that Business Intelligence explained about a concept and method of how to improve the quality of business decision making based on data-based systems [12].

From the three sources above, it can be concluded that Business Intelligence is the concept of collecting data, storing data and selecting data to provide information to help and improve the quality of business decision making for companies. So it can be said that the information system is a place for data entry, while the business intelligence application is a place for data analysis. Where the concept of business intelligence turns information into new knowledge and understanding for an organization.

\subsection{Data warehouse}

Data Warehouse is a database that contains data from several integrated, aggregated and structured operational systems so that it can be used to support analysis and decision making processes. Data warehouse is a concept and combination of technologies that facilitate organizations to manage and maintain historical data obtained from systems or operational applications [13].

Data warehouse has several characteristics, according to Inmon a data warehouse has the following main characteristics [14]:

a) Subject Oriented 
Subject-oriented data warehouse means that the data warehouse is designed to analyze data based on certain subjects in the organization, not on certain application processes or functions.

b) Integrated

Data Warehouse can store data that comes from separate sources into a format that is consistent and integrated with one another. Thus the data cannot be fragmented because the existing data is a unity that supports the whole concept of the data warehouse itself.

c) Nonvolatile

Data in a data warehouse cannot be changed or updated. Data in a data warehouse is different from operational data where in operational data, data can be changed, deleted or added, but the data warehouse data is readonly

d) Time Variant

In a data warehouse, each row of data must have a time component. For example the data record must have a transaction date that shows the time dimension in the data.

\subsection{Extract Transform Load (ETL)}

ETL (Extract, Transform, Load) is the basic system of data warehouse. A good ETL design of a data source extraction system, prioritizing data quality and consistent standards, data from separate sources accordingly, so that it can be integrated so as to provide a data format to be represented. The ETL system is a backbone activity that is not visible to the end user of the datawarehouse. ETL fulfills 70 percent of the resources needed in implementing and maintaining a data warehouse [15].

Extract, Transform and Load are also a collection of data preparation processes from OLTP (Online Transaction Process). ETL is the data processing phase of data sources entering the data warehouse. The purpose of ETL is to collect, filter, process and combine relevant data from various sources to be stored in a data warehouse [16].

\subsection{Pentaho Data Integration (PDI) kettle}

Pentaho Data Integration (PDI) Kettle is an Open Source software from Pentaho that can be used to integrate data. Kettle provides ETL (Extraction, Transformation and Loading) facilities. Kettle can be used to clean data, loading from file to database or vice versa and migration between applications in large volumes. The commercial version of Kettle is Pentaho Data Integration (PDI).

\subsection{Microsoft Power Bi}

Microsoft Power BI is a business intelligent software or a set of business analytics tools that can increase insight into agencies or organizations. Microsoft Power BI can connect up to hundreds of data sources, simplify data preparation, and drive adhoc analysis. The resulting report can be displayed on the web or mobile devices and is able to create a personalized dashboard with a 360 degree display. There are various forms of graphical visualization that can be used in Microsoft Power BI including stacked bar charts, stacked column charts, clustered bar charts, clustered column charts, line charts, area charts, stacked area charts, ribbon charts, pie charts, donut charts, treemaps, and others. Microsoft Power BI is integrated with Bing Maps to provide default map coordinates (a process called geo-coding) so that it can create a map display equipped with an algorithm to identify the correct location. Microsoft Power BI can verify geographic fields based on geo-coded fields by setting the data category in the data fields, by: selecting the desired table, then going to the Advanced Ribbon and setting the data category to the address, city, continent, country, ZIP code, state or province. Categories will help bing correctly encode the date.

\subsection{Cost accounting}

Cost accounting is the process of recording, classifying, summarizing and presenting the costs of making and selling products or services, in certain ways, as well as interpreting them [17]. The object of cost accounting activities is cost. The output of the application of cost accounting is the determination of the cost of production, controlling costs and supporting decision making for management. To determine the cost of production, cost accounting records, classifies and summarizes the costs of production costs, both the production of products / goods and services. The fees processed are historical costs resulting from the recap of the previous transaction.

\subsection{Cost object}

Cost object is an item or activity whose costs are accumulated and measured. Items and activities that can be object of cost are location, service, product, batch of similar units, 
customer, contract, product line, process, department, division and project. In this study, the cost objects used are location, service, customers, tools, and commodities [18].

The ability to track costs determines how objective, reliable and meaningful the resulting cost measures are and how confident decision makers are in understanding and relying on these cost measures as a basis for making predictions and making decisions. Common ways of classifying costs are:

a) Direct cost

Direct costs are costs that can be charged directly to cost objects or products.

b) Indirect costs

Indirect costs are costs that are difficult or cannot be attributed and charged directly to the unit of production, and are accurately traced to cost objects.

\subsection{Methodology}

The research methodology was obtained through studies literature and experiment/observation with using several stages including:
a) Literature study
b) Data collection
c) Selection of attributes
d) Application application
e) Evaluate results
f) Experimentation Documentation

Development of the cost accounting BI done with reference to the Business methodology Intelligence Roap Map model by Moss and Attre as follows:

The discussions carried out on business intelligence roadmap only covers the analysis phase as follows:

a) The Justification Phase

At the justification stage, a business case assessment process will be carried out, where at this stage there will be an identification of the business needs of PT XYZ. During the business case assessment stage, interviews will be conducted with PT XYZ's finance department to determine the revenue recording process, expense recording process, and cost accounting business processes. Interviews were also conducted to identify the current architecture and what operational systems have been used. Operational systems are needed as supporting data in processing output reports from cost accounting. If detailed, the things done at the business case assessment stage are as follows:

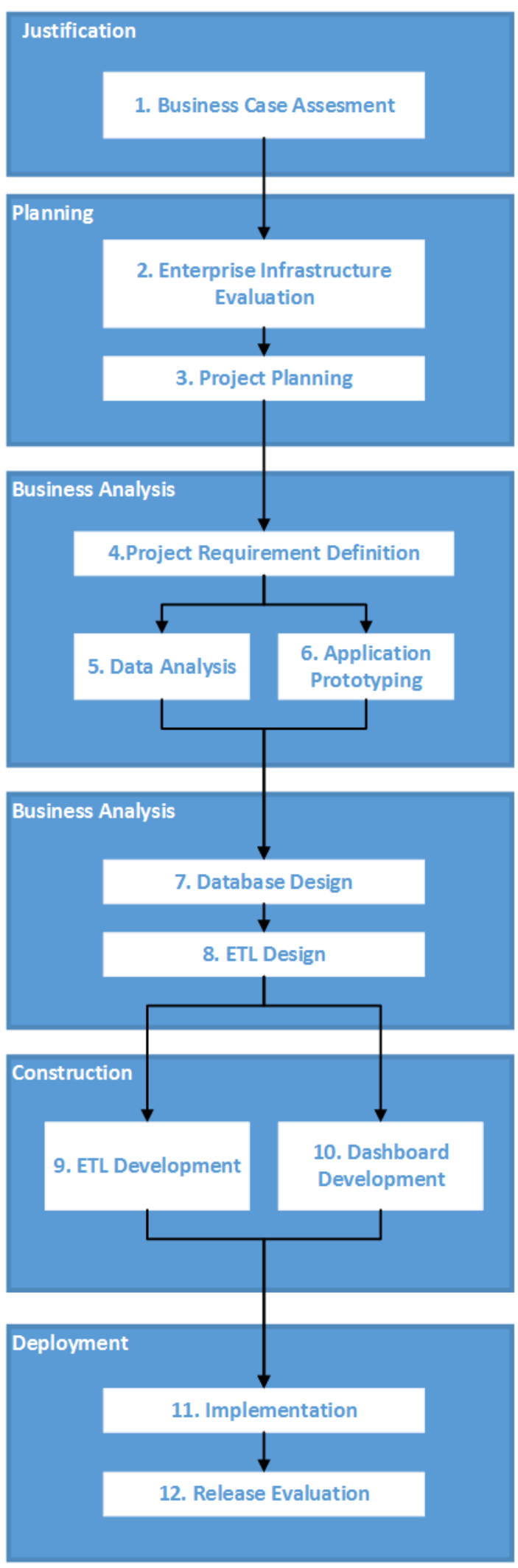

Figure 1: Business Intelligence Road Map 
1. Identify Business Needs

2. Identification of the Current System Architecture

3. Identification of Data Sources

4. BI Application Targets

b) Planning Phase

At the planning stage there are 2 main activities, namely enterprise infrastructure evaluation and project planning. In the enterprise infrastructure evaluation phase, an evaluation of:

1. Technical Infrastructure

Technical infrastructure evaluation includes evaluation of hardware, software, middleware, database management systems, operating systems, network components, meta data repositories, and others. The activities carried out at this stage are evaluating the ongoing platform, evaluating and selecting new products, writing technical infrastructure evaluation reports, and expanding the ongoing platform.

2. Non-Technical Infrastructure

Non-technical infrastructure evaluation includes evaluation of meta data standards, data-naming standards, enterprise logical data models, methods, instructions, testing procedures, change-control processes, procedures for issue management, and others. The activities carried out at this stage, namely evaluating the effectiveness of non-technical infrastructure components, producing nontechnical infrastructure evaluation reports, and improving non-technical infrastructure. In the project planning phase, an evaluation of BI projects are dynamic so that any changes that occur in the scope, staff, budget, technology, business processes can influence the success of a BI project. Therefore, project planning must be made more detailed and the latest progress must always be monitored and reported. The activities carried out at this stage, namely determining project needs, determining conditions from source files and databases, determining and revising cost estimates, revising risk management, identifying critical success factors, preparing project charter, preparing high level project planning, and running projects. In this study the steps undertaken are determining the project needs, determining and revising cost estimates and preparing a high-level project planning.

c) Business Analysis Phase

Make detailed analyzes of problems or business opportunities to get a solid understanding of business needs for potential solutions. Moss and Atre (2003) [5]. In this stage there are four activities carried out, namely:

1. Project Requirement Definition

In this stage we define what needs are needed. There are several ways to identify needs, namely by conducting internal meetings with users of PT XYZ and conducting literature studies.

2. Data analysis

Data analysis focuses on identifying the data source (source), logical design (ER-Diagram) and identifying the attributes.

3. Application Prototyping Protoype is built to be validated in accordance with specified business requirements. The results of the validation of the prototype were evaluated and their shortcomings were corrected

4. Metadata Analysis

Metadata is processed in the design and data sources are mapped to the metadata structure.

d) Design phase

At the design stage there are 2 main activities, namely:

1. Database design.

The BI database will hold all business data in detail and in the form of aggregation, depending on the reporting needs of the executive. Not all reporting needs are strategic and not all reporting needs are multidimensional. Each database design must match what is needed by executives. The activities carried out at this stage are reviewing data access needs, determining aggregation / summary needs, designing business intelligence databases, designing database structures physically, creating business intelligence databases, developing database maintenance procedures, preparing monitoring and tuning database designs, and prepare the design of monitoring and query tuning.

2. Extract / Transform / Load design. 
The ETL (Extract / Transform / Load) process is the most complex process in a BI project because this is where the quality of a data warehouse is taken into account, where the data validation process, data cleansing is done in the ETL process. The activities carried out at this stage are creating source-to-target mapping documents, conducting tests on the function of ETL tools, designing ETL process flow, designing ETL programs, and setting up ETL staging areas.

e) Construction Phase

At the construction stage there are 2 main activities, namely:

1. Extract / transform / load development Activities undertaken at the ETL development stage are testing the manufacturing and ETL processes, testing process integration, testing ETL process performance, ETL process quality assurance, and acceptance of the ETL process.

2. Application development

The application development process is the process of making an application after making a prototype. The process of making an application is adjusted based on a design that was previously created. The activities carried out at this stage are determining the needs of the final project, designing the application program, making and conducting unit testing of the application program, conducting application program tests, and providing data access and providing analysis training.

\section{f) Deployment Phase}

At the deployment stage there are 2 main activities, namely:

1. Implementation

At this stage the deployment process will be carried out on the BI database and applications. The activities carried out at this stage are planning implementation, building a production environment, installing all BI application components, setting up a production schedule, loading a production database, and preparing support.

2. Release evaluation

In the release evaluation stage an evaluation is carried out to produce a better and more efficient application. The activities carried out at this stage are preparing post-implementation reviews, organizing post-implementation review meetings, conducting meetings to review post-implementation, and following up on post-implementation meeting results.

\section{Results}

In accordance with the formulation of the problems discussed in section I, XYZ has a need for a system that can help provide financial accounting based on cost accounting. With the cost accounting based financial statements, it can help XYZ managers in determining the cost of production, controlling costs and supporting decision making.

One solution that can be done for the above needs is the adoption of the BI system. BI can be one of the tools to produce cost accounting reports in the form of a dashboard. Through this research it is expected to provide the best solution for XYZ according to their needs.

\subsection{Data Analysis and Design}

\subsubsection{Analysis information needs and data sources}

Information needs analysis is done with observe things that are needed at XYZ Company. Then conduct interviews and field observations. Based on the results of these methods, the information needs to be used to develop the BI model in XYZ companies include:

a) Business segmentation information based on location

b) Business segmentation information based on services

c) Business segmentation information based on customer

d) Business segmentation information based on equipment

e) Business segmentation information based on commodity

Data sources that will be used are operational data from the Oracle EBS application and Cartos application used by XYZ companies in carrying out company operational activities. 


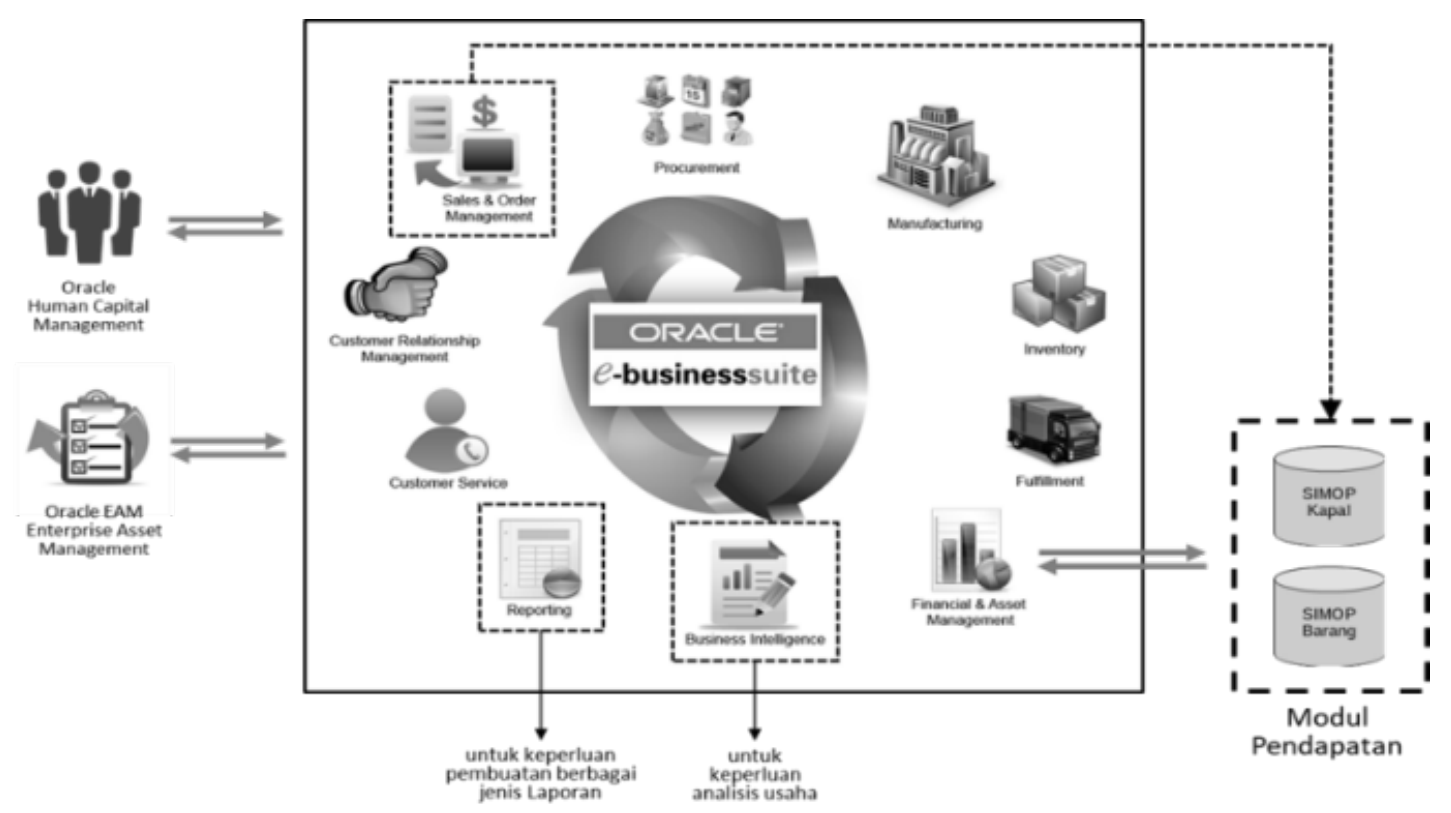

Figure 2: Logical Architecture

\subsubsection{Data warehouse design}

The data warehouse design is the design stage of the research methodology. The data warehouse design is carried out in several stages namely the design of data warehouse architecture, modeling, scheme design and ETL processes in the data warehouse. The data warehouse architecture design is divided into two, namely logical architecture design and physical architecture design.

a) Logical Architecture

In designing logical data warehouse architecture, the data used is sourced from Oracle EBS applications and Cartos applications. The next step taken is to filter the data to select the data needed because the data warehouse only contains data relating to the development of Business Intelligence for this research. The logical architecture design for the data warehouse can be seen in Figure 2.

b) Physical Architecture

Physical architecture is a technical description of the configuration applied. The physical architecture

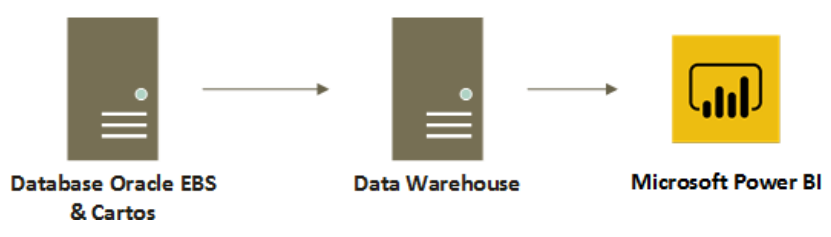

Figure 3: Physical Architecture design for the data warehouse can be seen in Figure 5.

\subsubsection{Data warehouse modeling}

The data warehouse modeling used is Fact Constellation Schema. Data warehouse is the result of selection from the Oracle EBS application database and cartos application after cleaning the data in accordance with research needs. The steps to build a data warehouse are as follows:

a) Business Process Selection The selection of business processes is the initial stage that must be done in making a data warehouse. Business processes taken in this research is the business process of recording company income and the business process of recording company costs.

b) Grain Selection

The next step is the selection of grain or granularity. Grains are information that will be represented by records from fact tables.

c) Dimension Identification

Dimensions contain descriptive explanations that have many attributes of a business. Dimension tables are detailed information of the dimension attributes in the fact table

There are 6 dimension tables built to form a data warehouse for the development of the XYZ company BI model. 
Table 1: Dimension Identification

\begin{tabular}{|c|c|c|}
\hline No & Dimension & Function \\
\hline 1 & Locations & Dimension table for storing location master data \\
\hline 2 & Services & Dimension table for storing services master data \\
\hline 3 & Customers & $\begin{array}{l}\text { Dimension table for storing customers master } \\
\text { data }\end{array}$ \\
\hline 4 & Periods & Dimension table for storing periods master data \\
\hline 5 & Equipments & $\begin{array}{l}\text { Dimension table for storing equipments master } \\
\text { data }\end{array}$ \\
\hline 6 & Commodites & $\begin{array}{l}\text { Dimension table for storing commoditiess mas- } \\
\text { ter data }\end{array}$ \\
\hline
\end{tabular}

\subsubsection{Identify the fact table}

This stage is determining the fact table that will be formed in the data warehouse. There is a fact table which is a journal transaction fact table. Existing facts will be processed and displayed in the form of Summary Report.

\subsubsection{Designing data warehouse schemes}

Based on the identification in the previous stage, a scheme and a relation for data warehouse are obtained. The data warehouse scheme can be seen in the Figure 4.
Table 2: Identify the fact table

\begin{tabular}{|c|c|c|}
\hline No & Fact Field & Explanation \\
\hline 1 & journal_id & $\begin{array}{l}\text { Contains the id of the fact table with an } \\
\text { integer type }\end{array}$ \\
\hline 2 & period_id & $\begin{array}{l}\text { Contains the id of the period dimen- } \\
\text { sion table with an integer type }\end{array}$ \\
\hline 3 & location_id & $\begin{array}{l}\text { Contains the id of the location dimen- } \\
\text { sion table with an integer type }\end{array}$ \\
\hline 4 & services_id & $\begin{array}{l}\text { Contains the id of the services dimen- } \\
\text { sion table with an integer type }\end{array}$ \\
\hline 5 & customer_id & $\begin{array}{l}\text { Contains the id of the customer dimen- } \\
\text { sion table with an integer type }\end{array}$ \\
\hline 6 & equipment_id & $\begin{array}{l}\text { Contains the id of the equipment di- } \\
\text { mension table with an integer type }\end{array}$ \\
\hline 7 & commodity_id & $\begin{array}{l}\text { Contains the id of the commodity di- } \\
\text { mension table with an integer type }\end{array}$ \\
\hline 8 & amount_revenue & Contains the amount of the revenue \\
\hline 9 & amount_bol & Contains the amount of the bol \\
\hline 10 & amount_botl & Contains the amount of the botl \\
\hline 11 & amount_bpo & Contains the amount of the bpo \\
\hline 12 & amount_bpkp & Contains the amount of the bpkp \\
\hline 13 & amount_expenses & Contains the amount of the expenses \\
\hline 14 & amount_profit_loses & $\begin{array}{l}\text { Contains the amount of the profit and } \\
\text { loses }\end{array}$ \\
\hline
\end{tabular}

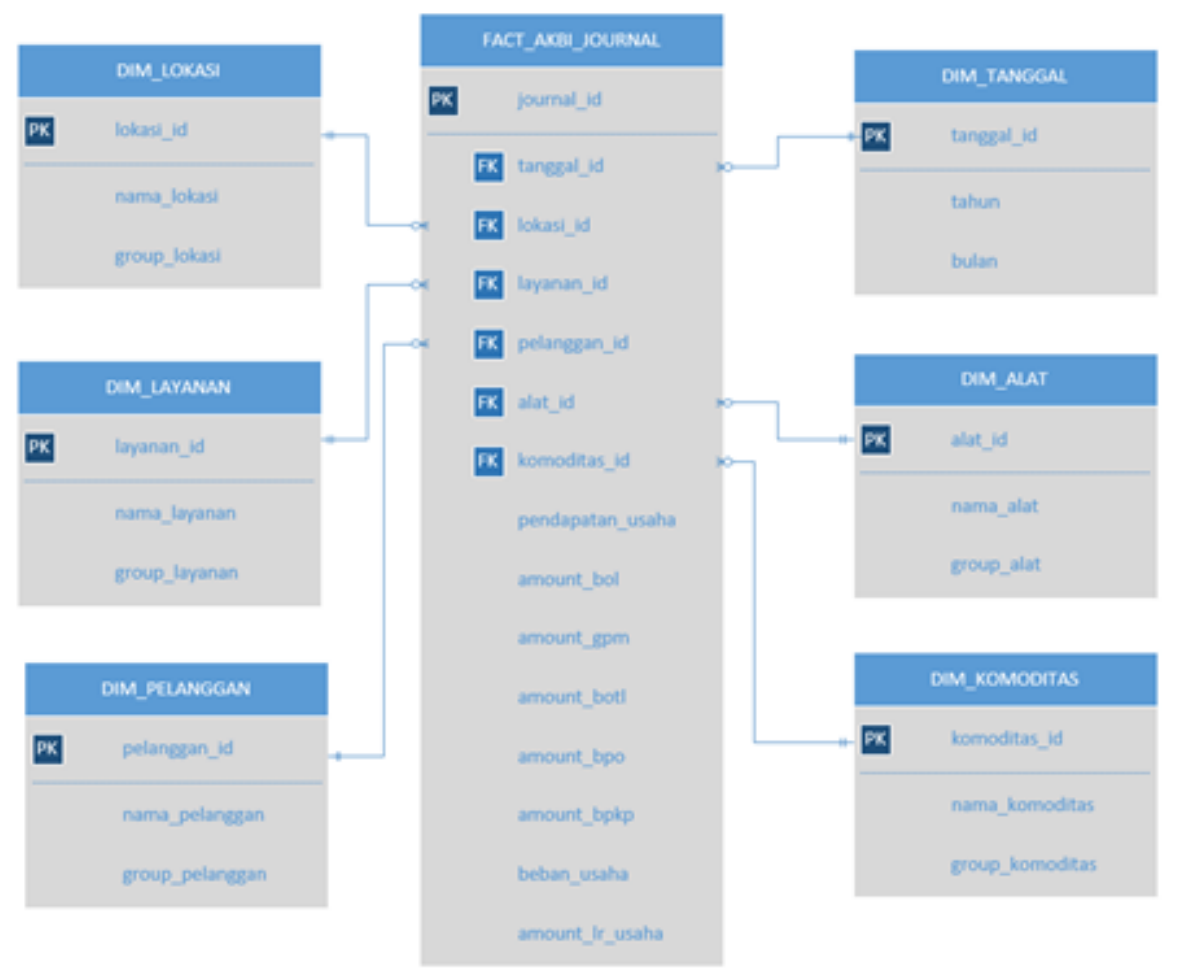

Figure 4: Data Warehouse Schemes 


\subsubsection{Extract, Transform, Loading (ETL) process}

ETL process is a process to move data from a database source (OLTP) into a data warehouse (OLAP). This ETL process uses the Pentaho Data Integration spoon application. Data warehouse stores data that is used to produce the information needed. The ETL process in this study uses the Pentaho Data Integration (PDI) tool. In PDI there are several icons used in the ETL process. The ETL process is carried out on 6 dimension tables and 1 fact table. One example of these ETLs can be seen in Figure 5 below.

\subsection{Application of Business Intelligence}

\subsubsection{Application of Microsoft Power BI}

Microsoft Power BI desktop is an analytic application for analyzing data. Microsoft Power BI can also be called a visualization tool used to represent data in a data warehouse. Before visualizing the data, the first step taken is to retrieve data from the data source by selecting get data on the initial display when opening the application. After that, a dialog box will appear to select the data source to be used. There are 5 types of data that can be used, namely

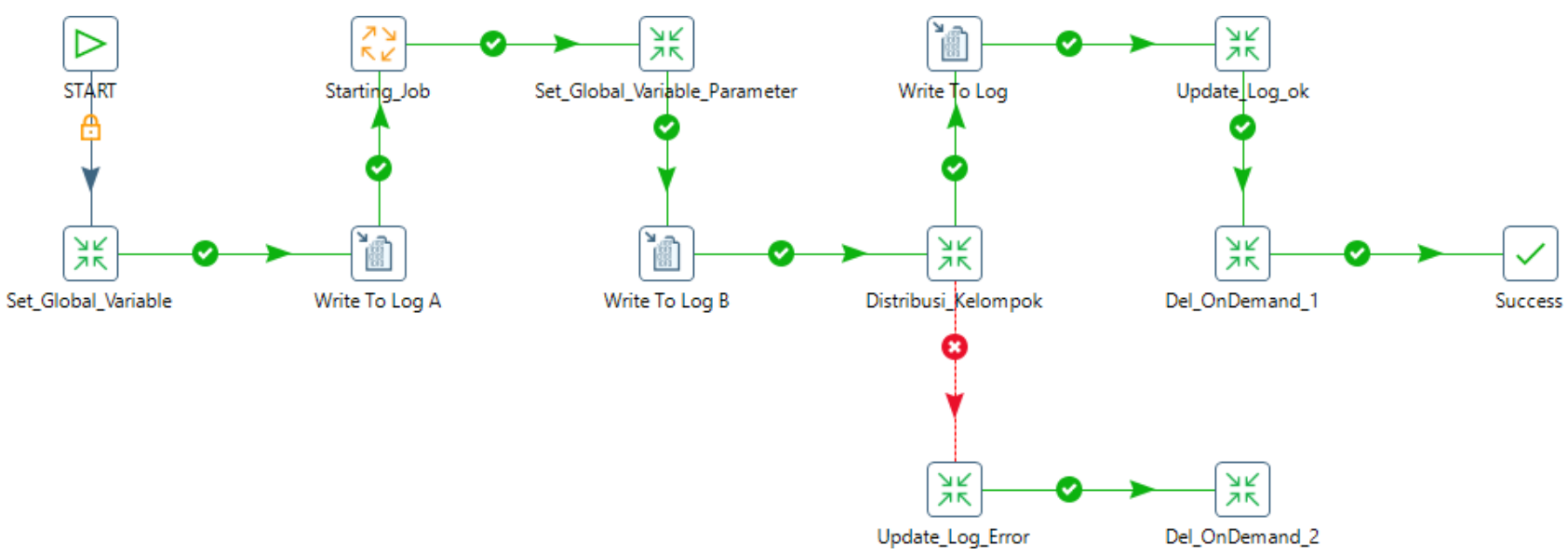

Figure 5: ETL Process

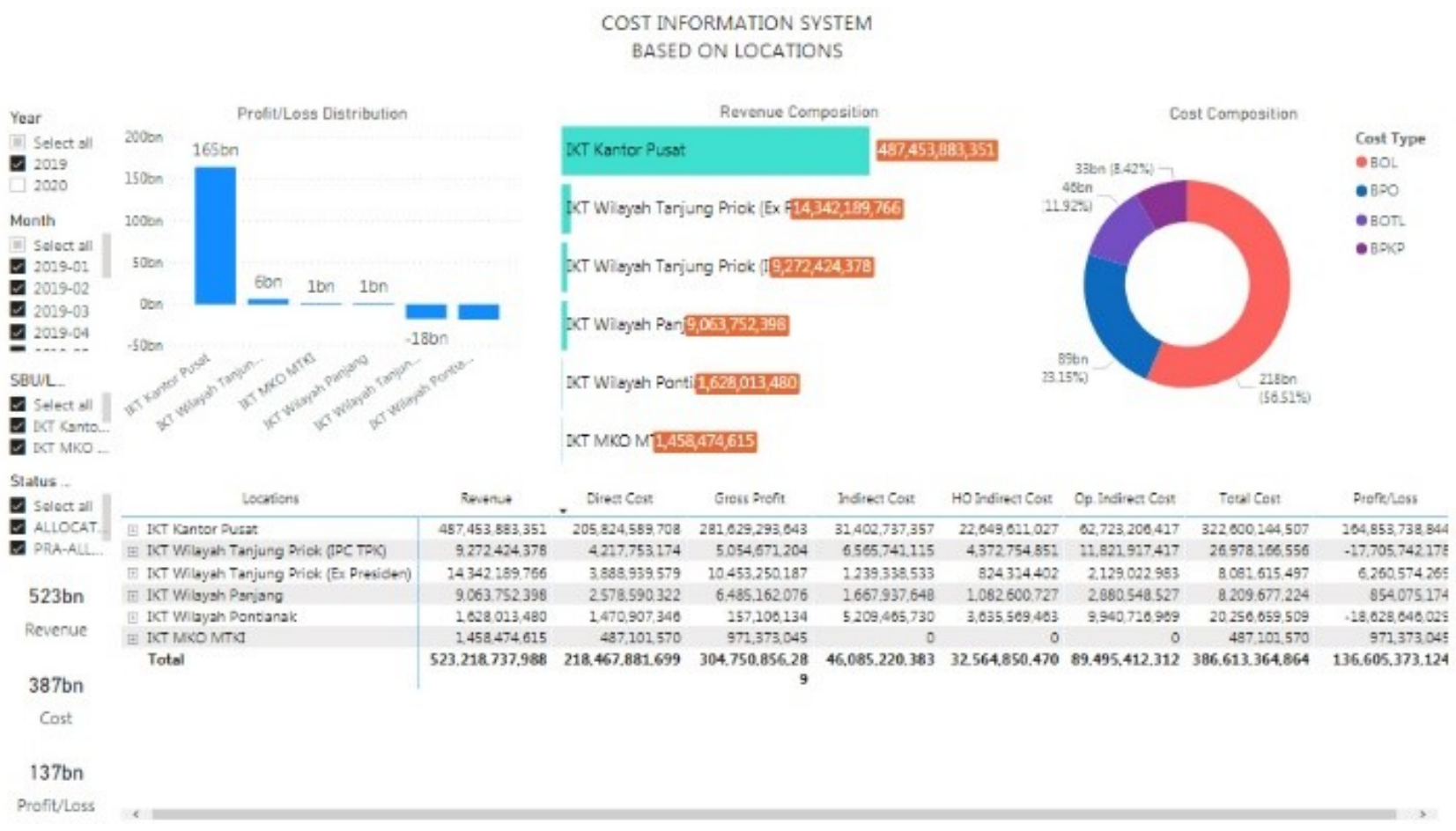

Figure 6: Cost Accounting Dashboard based on Location 
files, databases, Azure, online services, and others. In this study the data source used is an Oracle database. The visualizations used for developing the Business Intelligence model in this study are graphics and text. Visualization results are described in the form of a dashboard.

Figure 6 contains information on the composition of the company's revenue, costs, and profit and loss seen from the perspective of the company's location. In the cost per location financial statement, the income statement can be seen in the location group so that each location can be assessed.

Figure 7 contains information about the composition of costs from company XYZ based on company location. The composition of these costs is divided into four types of costs, BOL is a direct cost that is charged based on location, BOTL is an indirect cost that is charged based on location, $\mathrm{BPO}$ is an indirect cost of the operational portion that is charged based on location, BPKP is an indirect cost from the head office which charged based on location. with this cost distribution management can determine which location provides the greatest cost.

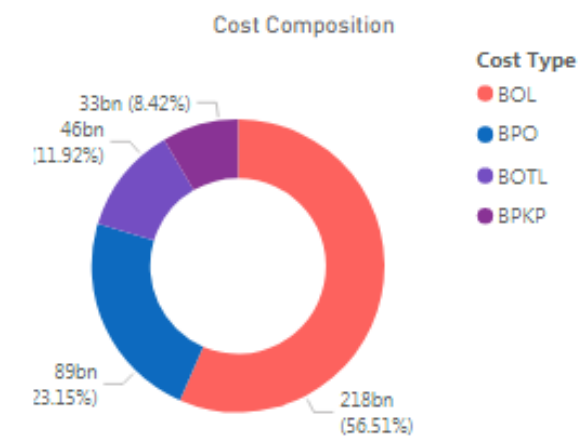

Figure 7: Cost Composition

Figure 8 contains information on the composition of XYZ company earnings based on company location. The income composition is divided into operational areas owned by the XYZ company. Management can monitor the revenue owned by each region through this dashboard

Figure 9 contains information on the distribution of profit and loss based on the company's operational area. Management can monitor the company's profit and loss from each region through this dashboard.

Figure 10 contains a filter for transaction periods consisting of years and months. With the period filter, each profit/loss, income and cost data can be seen based on the period of year and month that management requires.

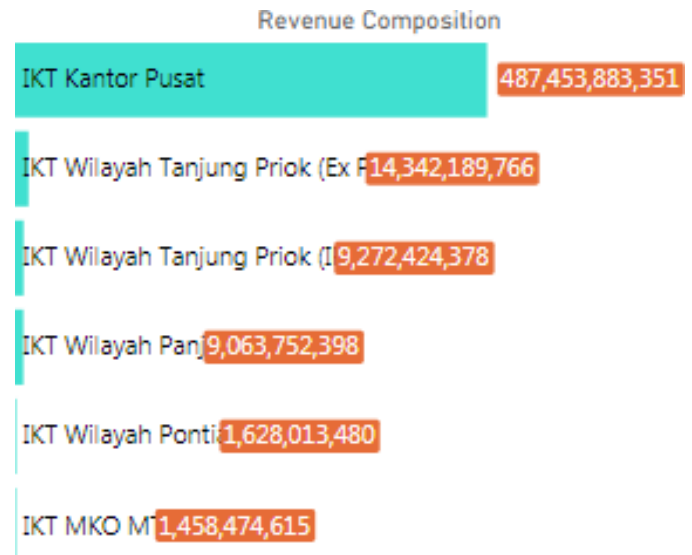

Figure 8: Revenue Composition

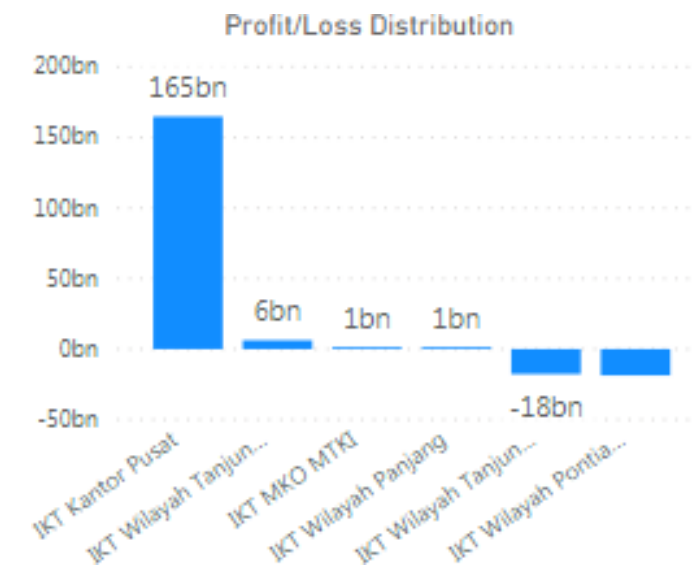

Figure 9: Profit/Loss Distribution

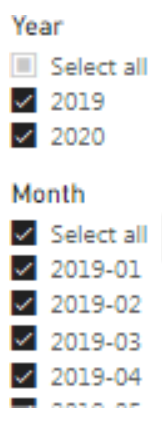

Figure 10: Filter Period

Figure 11 contains detailed information on revenue, direct costs, indirect costs and profit/loss for each area of the company location.

Figure 12 contains information on the composition of the company's revenue, costs, and profit and loss seen from the perspective of the company's services. In the cost of service accounting report, the income statement can be seen by service group so that the financial performance of each service can be evaluated. 


\begin{tabular}{|c|c|c|c|c|c|c|c|c|}
\hline Locations & Revenue & Direct Cost & Gross Profit & Indirect Cost & HO Indirect Cost & Op. Indirect Cost & Total Cost & Profit/Loss \\
\hline 由 IKT Kantor Pusat & $487,453,883,351$ & $205,824,589,708$ & $281,629,293,643$ & $31,402,737,357$ & $22,649,611,027$ & $62,723,206,417$ & $322,600,144,507$ & $164,853,738,844$ \\
\hline [1 IKT Wilayah Tanjung Priok (IPC TPK) & $9,272,424,378$ & $4,217,753,174$ & $5,054,671,204$ & $6,565,741,115$ & $4,372,754,851$ & $11,821,917,417$ & $26,978,166,556$ & $-17,705,742,178$ \\
\hline [1KT Wilayah Tanjung Priok (Ex Presiden) & $14,342,189,766$ & $3,888,939,579$ & $10,453,250,187$ & $1,239,338,533$ & $824,314,402$ & $2,129,022,983$ & $8,081,615,497$ & $6,260,574,269$ \\
\hline Ð IKT Wilayah Panjang & $9,063,752,398$ & $2,578,590,322$ & $6,485,162,076$ & $1,667,937,648$ & $1,082,600,727$ & $2,880,548,527$ & $8,209,677,224$ & $854,075,174$ \\
\hline \# IKT Wilayah Pontianak & $1,628,013,480$ & $1,470,907,346$ & $157,106,134$ & $5,209,465,730$ & $3,635,569,463$ & $9,940,716,969$ & $20,256,659,509$ & $-18,628,646,029$ \\
\hline Đ IKT MKO MTKI & $1,458,474,615$ & $487,101,570$ & $971,373,045$ & 0 & 0 & 0 & $487,101,570$ & $971,373,045$ \\
\hline Total & $523,218,737,988$ & $218,467,881,699$ & $\begin{array}{r}304,750,856,28 \\
9\end{array}$ & $46,085,220,383$ & $32,564,850,470$ & $89,495,412,312$ & $386,613,364,864$ & $136,605,373,124$ \\
\hline
\end{tabular}

Figure 11: Filter Period

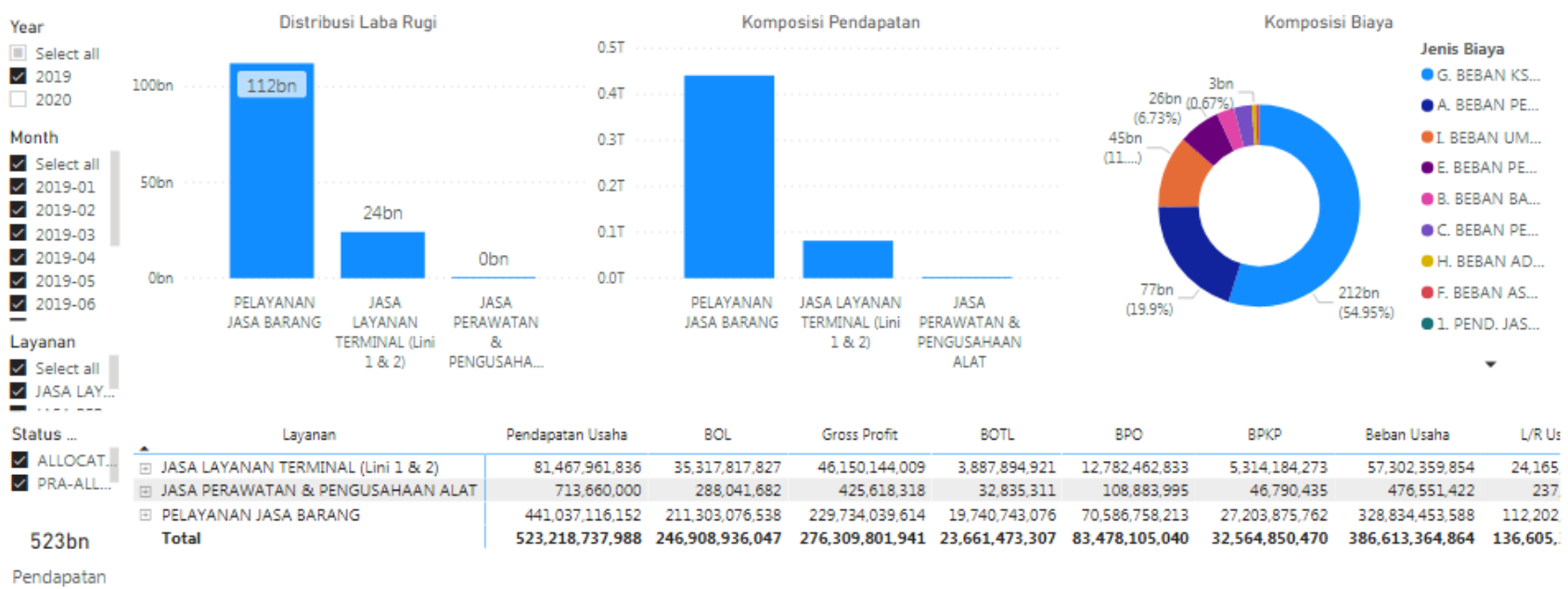

\section{7bn \\ Biaya}

$137 \mathrm{bn}$

Profit/Loss

Figure 12: Cost Accounting Dashboard based on Services

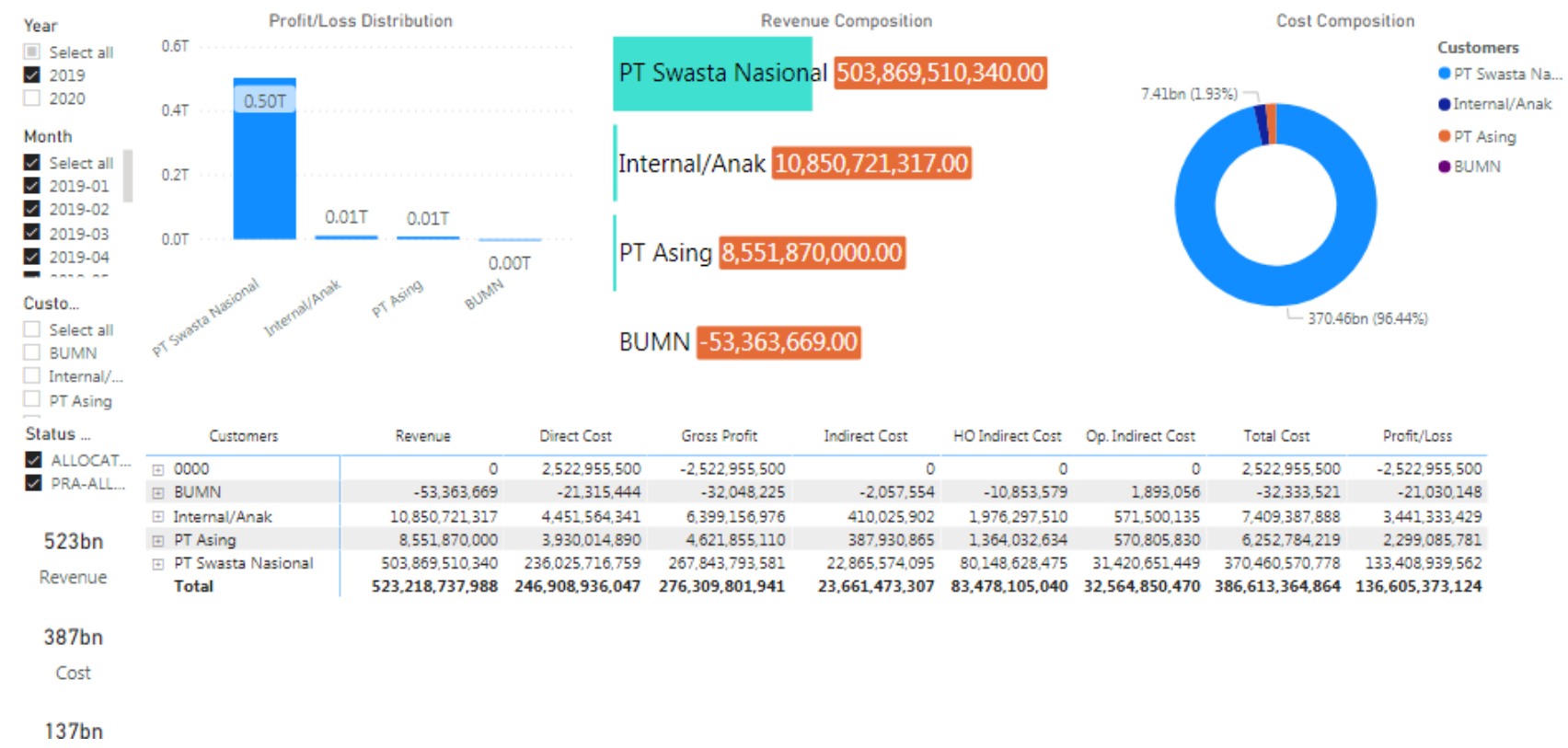

Figure 13: Cost Accounting Dashboard based on Customers 


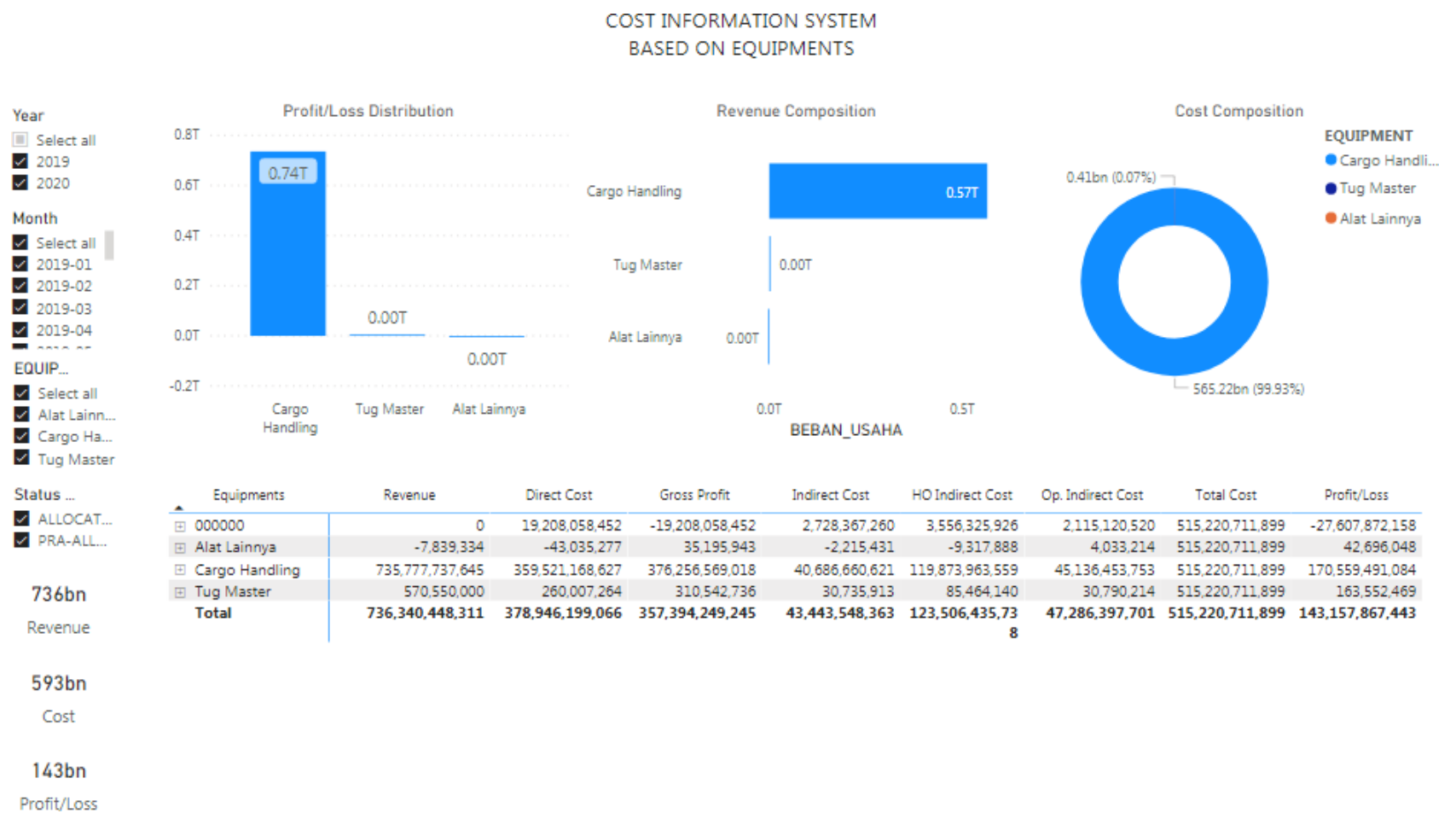

Figure 14: Cost Accounting Dashboard based on Equipments

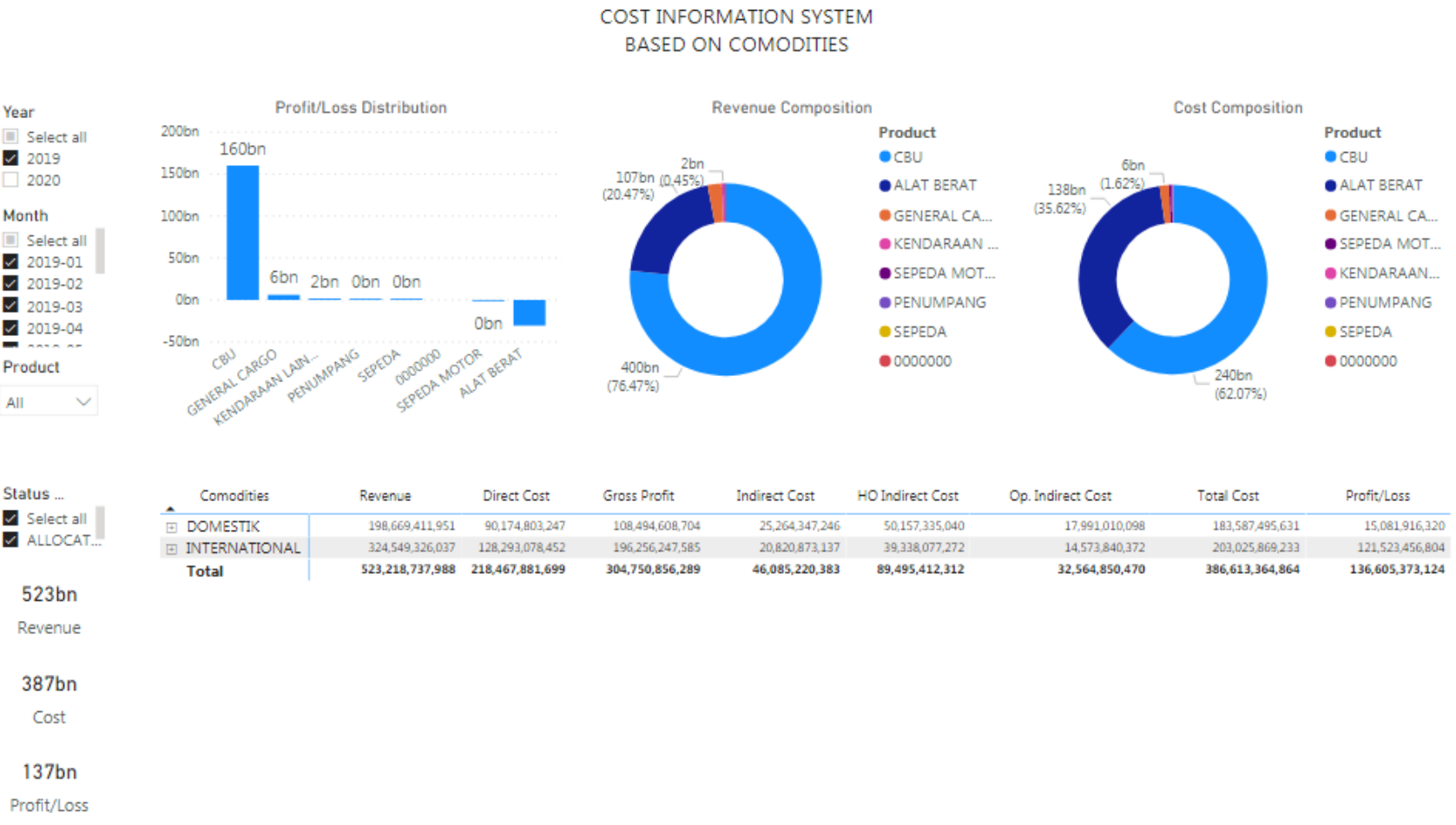

Figure 15: Cost Accounting Dashboard based on Commodities

Figure 13 contains information on the composition of the company's revenue, costs, and profit and loss seen from the perspective of the company's customers. In the cost of customer accounting report, the income statement can be seen by customer group so that the revenue generated and costs incurred from each customer can be evaluated. 
Figure 14 contains information on the composition of the company's revenue, costs, and profit and loss seen from the perspective of the company's equipments. In the cost of equipment accounting report, the income statement can be seen based on the group of tools so that the income generated and costs incurred from each equipment owned by XYZ can be evaluated.

Figure 15 contains information on the composition of the company's revenue, costs, and profit and loss seen from the perspective of the company's commodities. In the cost of commodity accounting report, the income statement can be seen by commodity group so that the revenue generated and costs incurred from each commodity served by XYZ can be evaluated.

\subsection{Release Evaluation}

There are 3 types of evaluations carried out namely, evaluation of the time of processing and visualization of data, evaluation of the use of disk space for data warehouse, and questionnaires to determine the usefulness and efficiency of the Business Intelligence system that has been implemented.

\subsubsection{Evaluation of data processing and visualization}

In this section an evaluation of the processing time and data visualization in the ETL process is carried out. The following time ETL on the Business Intelligence system that has been implemented:

Table 3: Evaluation of data processing and visualization

\begin{tabular}{|c|c|c|c|c|}
\hline Date & Table & Start & End & Time \\
\hline \multirow[t]{6}{*}{$27-F e b-20$} & GL_CODE_COMBINATION & $1: 01: 22$ & $1: 05: 23$ & 0:04:01 \\
\hline & GL_JE_LINES & $1: 05: 23$ & $1: 12: 46$ & $0: 07: 23$ \\
\hline & GL_JE_HEADER & $1: 12: 46$ & $1: 16: 48$ & 0:04:02 \\
\hline & GL_PERIODS & $1: 16: 48$ & $1: 19: 48$ & 0:03:00 \\
\hline & GL_IMPORT_REFERENCES & 1:19:48 & $1: 25: 47$ & $0: 05: 59$ \\
\hline & GL_BALANCES & $1: 25: 47$ & $1: 33: 33$ & 0:07:46 \\
\hline \multicolumn{4}{|c|}{ Total Time } & $0: 32: 11$ \\
\hline \multirow[t]{6}{*}{ 28-Feb-20 } & GL_CODE_COMBINATION & $1: 01: 22$ & $1: 05: 23$ & 0:04:01 \\
\hline & GL_JE_LINES & $1: 05: 23$ & $1: 11: 00$ & $0: 05: 37$ \\
\hline & GL_JE_HEADER & $1: 11: 00$ & $1: 17: 32$ & $0: 06: 32$ \\
\hline & GL_PERIODS & $1: 17: 32$ & $1: 20: 06$ & $0: 02: 34$ \\
\hline & GL_IMPORT_REFERENCES & $1: 20: 06$ & $1: 24: 45$ & $0: 04: 39$ \\
\hline & GL_BALANCES & $1: 24: 45$ & $1: 31: 01$ & $0: 06: 16$ \\
\hline \multicolumn{4}{|c|}{ Total Time } & $0: 29: 39$ \\
\hline \multirow[t]{6}{*}{ 29-Feb-20 } & GL_CODE_COMBINATION & $1: 01: 33$ & $1: 05: 23$ & $0: 03: 50$ \\
\hline & GL_JE_LINES & $1: 05: 23$ & $1: 10: 00$ & $0: 04: 37$ \\
\hline & GL_JE_HEADER & $1: 10: 00$ & $1: 16: 21$ & $0: 06: 21$ \\
\hline & GL_PERIODS & $1: 16: 21$ & $1: 21: 22$ & 0:05:01 \\
\hline & GL_IMPORT_REFERENCES & $1: 21: 22$ & $1: 28: 55$ & $0: 07: 33$ \\
\hline & GL_BALANCES & $1: 28: 55$ & $1: 33: 17$ & $0: 04: 22$ \\
\hline \multicolumn{4}{|c|}{ Total Time } & $0: 31: 44$ \\
\hline \multirow[t]{6}{*}{ 01-Mei-20 } & GL_CODE_COMBINATION & $1: 01: 22$ & $1: 05: 46$ & $0: 04: 24$ \\
\hline & GL_JE_LINES & $1: 05: 46$ & $1: 14: 20$ & $0: 08: 34$ \\
\hline & GL_JE_HEADER & $1: 14: 20$ & $1: 15: 49$ & $0: 01: 29$ \\
\hline & GL_PERIODS & $1: 15: 49$ & $1: 22: 00$ & $0: 06: 11$ \\
\hline & GL_IMPORT_REFERENCES & $1: 22: 00$ & $1: 28: 31$ & 0:06:31 \\
\hline & GL_BALANCES & $1: 28: 31$ & $1: 32: 56$ & $0: 04: 25$ \\
\hline \multicolumn{4}{|c|}{ Total Time } & $0: 31: 34$ \\
\hline \multicolumn{4}{|c|}{ Average Time } & $0: 31: 17$ \\
\hline
\end{tabular}


By looking at the table above, we can see that the time needed to do the ETL process is 31 minutes 17 seconds. Data processing using the Business Intelligence system is faster, when compared to the manual process performed using the Microsoft Excel application that is for 2 weeks.

\subsubsection{Evaluation disk space usage}

The amount of disk space usage in the Business Intelligence system is $1229 \mathrm{MB}$ per month with annual growth of $14,748 \mathrm{MB}$. With the use of a hard disk in a virtual database of $200 \mathrm{~GB}$, the implemented Business Intelligence system can hold corporate data for a span of 14 years.

Table 4: Evaluate disk space usage

\begin{tabular}{llll}
\hline No & Module & $\begin{array}{l}\text { Amount of } \\
\text { data }\end{array}$ & Size (KB) \\
\hline 1 & GL_CODE_COMBINATION & 603,291 & 434176 \\
2 & GL_JE_LINES & $1,313,384$ & 811008 \\
3 & GL_JE_HEADER & 7578 & 5120 \\
4 & GL_PERIODS & 4916 & 3072 \\
5 & GL_IMPORT_REFERENCES & 1565 & 2048 \\
6 & GL_BALANCES & 3832 & 3072 \\
\hline Total in Month & & $\mathbf{1 2 2 9} \mathbf{M B}$ \\
\hline Growth in Year & & $\mathbf{1 4 7 4 8} \mathbf{~ M B}$ \\
\hline
\end{tabular}

\section{Conclusion}

With the implementation of the Business Intelligence system, companies can generate income statements for companies per location, service, customer, tool and commodity. With time processing and data visualization increased faster than the previous process (using the Microsoft Excel application) which is for 2 weeks to 31 minutes. The company can display information on the company's profit and loss historically. With the amount of data that can be stored is 200 Giga Bytes or historical data within a period of 14 years. The company can produce information about the company's profit and loss in Real Time. Where by installing the scheduler every day at 4 am and processing time for 31 minutes, the report can be accessed one day after the last transaction was made. The visualization presented in the graph on the dashboard makes it easy for executives to see information about expenses used based on location used, services used, customers served, tools used and commodities used. With the existence of a cost accounting report in the dashboard, XYZ company can control costs for divisions that are considered unprofitable. So then the company's operational activities can be more effective and efficient.

\section{References}

[1] Chen H, Chiang RH, Storey VC. Business Intelligence and Analytics: From Big Data to Biglmpact. Manage Inf Syst Q. 2012;36(4):1165-88.

[2] Foshay N, Kuziemsky C. Towards an implementation framework for business intelligence in healthcare. Int J Inf Manage. 2013;34(1):20-7.

[3] Hartley, Kaashief \& Seymour, Lisa. (2011). Towards a framework for the adoption of business intelligence in public sector organisations: the case of South Africa. 116-122. https://doi. org/10.1145/2072221.2072235.

[4] Ali-Ozkan. Osama \& Nassif, Ali \& Capretz, Luiz. (2013). Business Intelligence Solutions in Healthcare A Case Study: Transforming OLTP system to BI Solution. 2013 3rd International Conference on Communications and Information Technology, ICCIT 2013. https://doi.org/10.1109/ICCITechnology.2013.6579551.

[5] Moss LT, Atre S. Business intelligence roadmap: The complete project lifecycle for decision-support applications. Pearson Education, Inc.; 2003.

[6] Iskandar, K., Jambak, M. I., Kosala, R., \& Prabowo, H. (2017). Current Issue on Knowledge Management System for future research: A Systematic Literature Review. Procedia Computer Science, 116(Iccsci), 68-80. https://doi.org/10.1016/j. procs.2017.10.011.

[7] Mariani M, Baggio R, Fuchs M, Höepken W. Business intelligence and big data in hospitality and tourism: a systematic literature review. Int J Contemp Hosp Manag. 2018;30(12):3514-54.

[8] Rikhardsson P, Yigitbasioglu O. Business intelligence $\&$ analytics in management accounting research: status and future focus. Int J Account Inf Syst. 2018;30:37-58.

[9] Moss LT, Atre S. Business intelligence roadmap: The complete project lifecycle for decision-support applications. Pearson Education, Inc.; 2003.

[10] David, Edward. 2000. "Business Intelligence, Have We Forgotten the Basics", white paper from www.bitpipe.com

[11] Al-Natsheh HT, et al. 2010. Commercializing Computational Intelligence Techniques In A Business Intelligence Application. Congress Evolutionary Computation (CEC), IEEE Congress on Digital Object Identifier. p 1 - 7 IEEE Conferences.

[12] Power, D.J. 2002, "Decision support systems: Concepts and resources for managers". United State of America: Green Wood Publishing Group.

[13] Mallach EG. Decision Support and Data Warehouse Systems. Singapore: Irwin McGraw Hill; 2000.

[14] Inmon WH. Building Data Warehouse. 3rd ed. Canada: John Wiley \& Sons; 2005.

[15] Kimball R, Ross M. The Data Warehouse Toolkit: The Complete Guide to Dimensional Modeling. 2nd ed. Canada: John Wiley \& Sons, Inc.; 2002. 
[16] Turban E, Aronson JE, Liang TP, Sharda R. Decision support and business intelligence systems. Pearson Education; 2005.

[17] Mulyadi. (2016). Sistem Informasi Akuntansi. Jakarta: Salemba Empat.
[18] Sanzhar A, Alinur M. Environmental Cost Accounting and Importance of Activity Based Costing for Management. Journal of Humanities Insights. 2019;03(04):226-31. 